\title{
On the measurement of the electromotive force of the pile
}

\section{M.J.-B. Baille}

To cite this article: M.J.-B. Baille (1881) On the measurement of the electromotive force of the pile, Philosophical Magazine Series 5, 11:66, 153-155, DOI: 10.1080/14786448108626990

To link to this article: http://dx.doi.org/10.1080/14786448108626990

曲 Published online: 12 May 2009.

Submit your article to this journal $\pi$

Џll Article views: 2

Q View related articles $\sqsubset$ 


\section{$\left[\begin{array}{ll}153 & ]\end{array}\right.$}

XXII. Intelligence and Miscellaneons Articles.

\section{ON THE MOTION OF AN INCOMPRESSIBLE VISCOUS FLUID IN THE VICINITY OF A SPHERE.}

To the Editors of the Philosophical Magazine and Journal.

Gentremen,

Halle a. S., Dec. 29, 1880.

TN the November number of the Philosophical Magazine (vol. $x$. No. 63), pp. 342-357, is a paper by Dr. Thomas Craig, of Washington, communicated by A. G. Greenhill, Esq., "On Steady Motion in an Incompressible Viscous Fluid." The second part of that paper treats of the motion of the fluid in the vicinity of a sphere. In the year 1875, in Borchardt's Journal für reine und angewandte Mathematik, vol. 1xxxi., I discussed the same question : I place at your disposal the enclosed copy of my paper. You will easily convince yourselves, by the perusal of $\S 2$ (pp. 68-74) of the same, that :-

(1) Mr. Craig and I have set and discussed exactly the same problem ;

(2) There is a close correspondence between the transformations and calculations in the one paper and in the other (I mention especially that Dr. Craig likewise makes use of a theorem of Borchardt's, Monatsberichte der Berl. Akad. 1873, in the same way as I had done);

(3) Of course our final results are identical.

I therefore venture to hope that you will give as early insertion as possible to this in the Philosophical Magazine.

Dr. A. Oberbeck, Professor at the

University of Halle a. d. Saale.

ON THE MEASUREMENT OF THE ELECTROMOTIVE FORCE OF THE PILE. BY M. J.-B. BAILLE.

The relative electromotive force of the pile is usually deduced from Ohm's laws and the examination of the intensity of the cur rents produced by it. When one wishes to measure these forces directly and to express them in absolute value, the very ingenious apparatus of Sir W. Thomson is ordinarily employed; but these instruments require delicate management, and the indications given by them are not always free from doubt. The study which $\mathbf{M}$. Cornu and I have made of the torsion-balance for our experiments

Phil. Mag. S. 5. Vol. 10. No. 66. Feb. $1881 . \quad$ M 
on the density of the earth led me to think that this apparatus, the construction and regulation of which are so simple, might be put in action by the weakest forces and give very precise measurements.

The precautions necessary for obtaining good oscillations consist in avoiding some perturbations which present themselves, always the same, and the relative influence of which would be the greater the more delicate the phenomenon to be studied.

Among those perturbations, M. Cornu and I have already pointed out electric influences and trepidations of the ground. These are completely eliminated by surrounding the apparatus with a metallic case attached to the ground, and setting it up in a very quiet place upon solid pillars.

I have been exposed to another very serious disturbing cause - the influence of heat. It makes itself sensible upon the torsion-thread, and upon the air of the case which surrounds the lever. These two effects are easily distinguished from one another. When the thread alone is heated or cooled, the oscillations are quite irregular and disordered; if the air alone is subjected to the action of the heat, the oscillations remain nearly pendular, but the point of static equilibrium about which the oscillation takes place is more or less quickly displaced, al ways in the same direction, while the duration of an oscillation is slightly increased. I protected myself from these very tenacious perturbing influences by surrounding the apparatus with a thick layer of wood-shavings.

The apparatus which I employed was composed of a long torsionthread (270 centims.) of annealed silver, and a lever 50 centims. in length, carrying at each end a ball of gilt copper of 3 centims. diameter. Similar spheres were fixed to the vertices of a rectangle of 20.5 metres, and communicated with each other in pairs diagonally. The lever, placed at equal distance from the fixed spheres, communicated, through the intermedium of the torsion-thread, with the positive pole of a determined pile $\mathrm{P}$, the other pole being to earth.

The charge of the lever was not so constant as I could have desired; for piles always undergo variations difficult to define. I was also obliged to measure this charge at each observation. I connected the positive pole of the pile $\mathbf{P}$ simultaneously with the lever and a pair of fixed spheres, and took the resulting deflection; I recommenced by taking the deflection on the other side, and so on alternately four times.

The pile to be measured, $X$, was composed of ten equal elements ; and $I$ put one of the poles of this pile into communication with the fixed balls, while the lever remained in contact with $P$, and the other pole of $X$ was to earth; then I measured the charge of the lever a second time.

The deflections were read by means of the reflection of an illuminated glass scale placed at 3.5 metres from the lever. All the elements of the measurement were known; and Coulomb's static 
formula gave

with

$$
\mathrm{C} \alpha=\frac{4 m m^{\prime}}{d^{2}}
$$

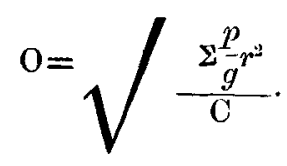

In my experiments $\mathrm{O}=437^{\mathrm{s}}$, and $\Sigma p r^{2}=32171 \cdot 6$ centimetregrammes, the lever having been made of a geometrical form.

The following numbers represent the potential of an element of the pile- that is to say, the quantity of electricity which would be shed by the pole of that pile upon a sphere of 1 centim. radius; they are expressed in electric units, the unit being the quantity of electricity which, acting upon itself at 1 centin. distance, produces a repulsion equal to 1 gramme.

Voltaic pile ............... 0.03415 , circuit open.

Pile (zine, sulphate of copper, copper) 0.02997, "

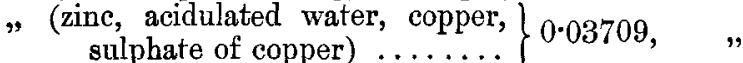

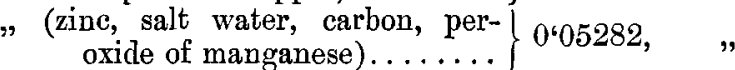

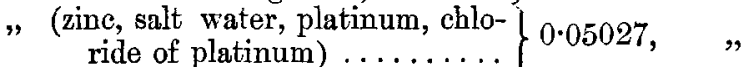

$\left." \begin{array}{c}\text { (zinc, acidulated water, carbon, } \\ \text { nitric acid) ............ }\end{array}\right\} 0.06285$,

These numbers are maxima values, obtained at the moment when the pile had just been charged; but these potentials rapidly grow less as the pile gets older. The sulphate-of-copper pile alone remains for a pretty long time near the given number; but it undergoes variations which may reach one twelfth of its value, more or less.-Comptes Rendus de l'Acad. rles Sciences, Jan. 3, 1881, t. xcii. pp. $32-34$.

\section{A STUDY ON SPECTROPHOTOMETERS. BY M. A. CROVA.}

The comparison of two spectra proceeding from two different sources of light is easily obtained by covering half the slit of a photometric spectroscope with a smali rectangular prism, of which the edge cuts the slit normally into two parts. One half receives one of the lights directly, the other by total reflection the other light placed laterally. In this case the slit must be horizontal; and if the prism is well cut and free from aberration, the clean image of the spectral lines and that of the edge of the prism are obtained simultaneously - the latter appearing as a very fine line separating the two spectra to be compared from one another. 